Medicine in the elderly

\title{
Coronary artery disease, valvular heart disease, bradycardia, and heart failure
}

\author{
E Smith, H Powell, IR Hastie
}

\section{Case history}

The patient is a 76-year-old man with a long history of stable angina having increasing frequency of pain at rest. Despite medical treatment he had ongoing rest pain and ECG evidence of ischaemia (figure 1). Emergency coronary arteriography was performed (figure 2) and he had emergency surgery, undergoing quadruple grafting using combined arterial and saphenous vein conduits. The procedure and post-operative course were uncomplicated and he returned home seven days later.

Box 1

Keywords: elderly, thrombolysis, heart failure, ACE inhibitors, angina, coronary artery bypass grafting, valvular heart disease, bradycardia

Division of Geriatric Medicine, St George's Hospital Medical School, London SW17 ORE, UK

E Smith

H Powell

IR Hastie

Correspondence to IR Hastie

Accepted 8 June 1994
Diseases of the circulatory system account for approximately half of all deaths in the UK, with coronary heart disease accounting for over half of these. Rheumatic valvular heart disease is becoming less common, but with an ageing population degenerative valve disease is increasing. ${ }^{1} \mathrm{With}$ improved technology available for the diagnosis and management of heart disease it will become ever more necessary to judge patients' suitability for a range of cardiological interventions based on the likely benefits and risks, and not purely on age alone. ${ }^{2}$ The ethical dilemma of elderly patient selection must be solved on the basis of knowledge of the morbidity, mortality, and probable symptomatic benefit. ${ }^{3}$

\section{Thrombolytic therapy}

It is now well established that elderly patients can benefit, in terms of survival, as much or more than younger patients from the administration of thrombolysis following acute myocardial infarction..$^{4-6}$ Despite this, in the US, patients aged over 75 are six times less likely to receive thrombolysis than younger patients, ${ }^{7}$ and in the UK, as recently as $199140 \%$ of coronary care units operated an age-related admissions policy for the administration of thrombolysis. ${ }^{8}$ Others have shown a longer delay time from the onset of symptoms to administration of treatment in elderly patients. ${ }^{9}$ This may be due to atypical symptoms or to nihilistic assumptions about the possible benefits by both patients and doctors. One of the reasons cited for the reduced use in elderly patients is the fear of haemorrhage, particularly intracranial. ${ }^{10}$ Overall there seems to be an incidence of around $1 \%$ for intracranial haemorrhage, but this is three times more common in the over-65s, ${ }^{11}$ and is associated with the use of the relatively fibrin-specific agents such as tissue plasminogen activator. Indeed, bleeds of all types and severity are more common in elderly patients, particularly where heparin was added to the regime, ${ }^{12}$ but the benefits still outweigh the risks.

\section{Angina}

Coronary artery disease is not only more common in older people but it is usually more severe, with greater frequency of left main stem and three-vessel disease. ${ }^{13}$ The three broad options for it management are medical, percutaneous intervention, and surgery.

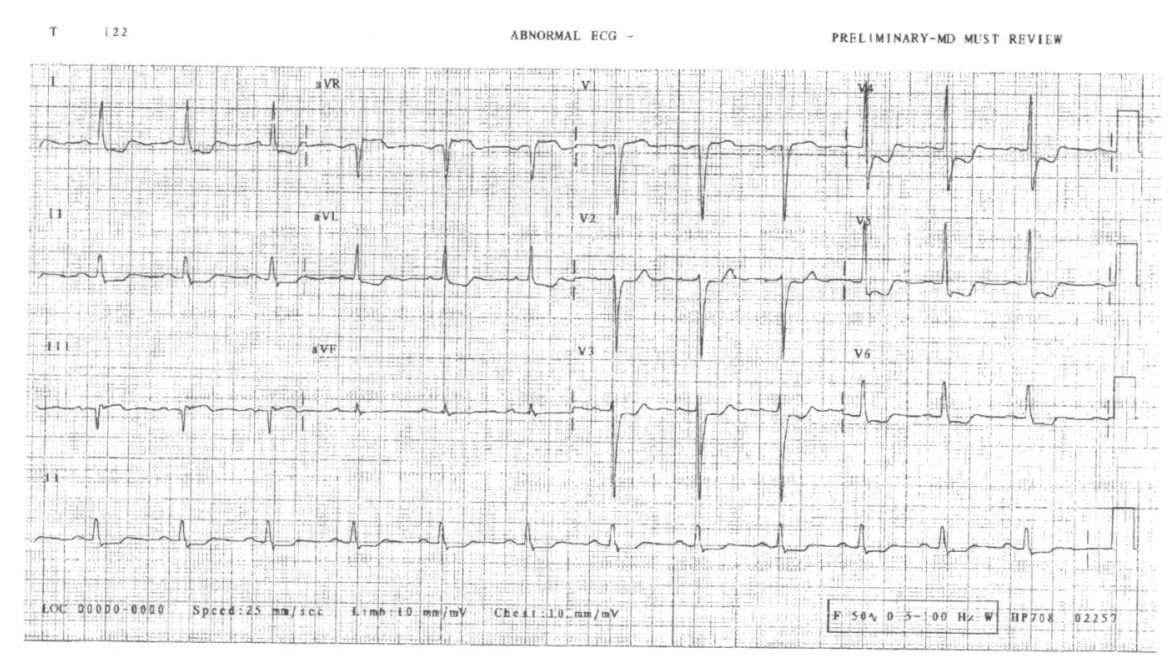

Figure 1 12-lead ECG showing wide-spread ST depression indicative of ischaemia 


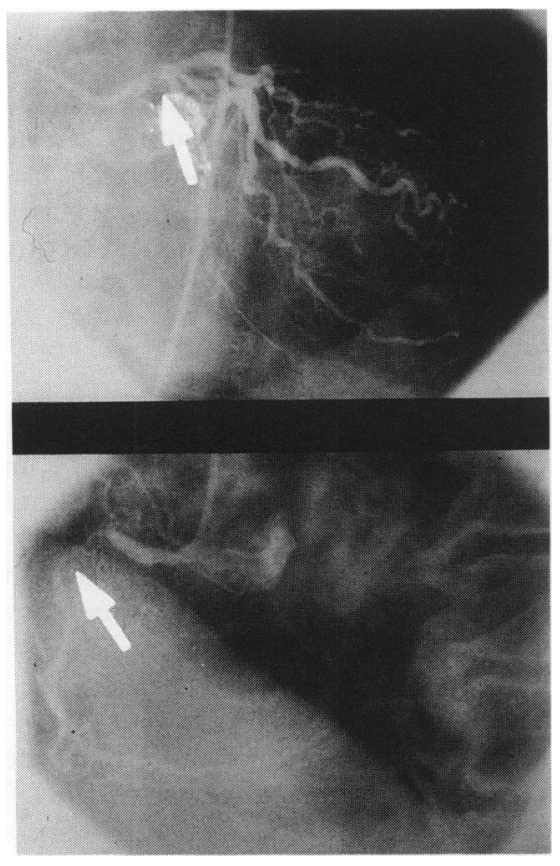

Figure 2 (upper) Postero-anterior view of left coronary artery. Arrow demonstrates critical left main stem stenosis. (lower) Left anterior oblique view of right coronary artery. Arrow demonstrates long segment of occlusion in the proximal right coronary artery
MEDICAL THERAPY

Medical therapy is often limited by the frequency of adverse drug reactions. In the older patient the number of pacemaker cells in the sinoatrial node is reduced by $90 \%,{ }^{13}$ so they are more susceptible to sinoatrial depression from drugs.

Increasingly, elderly people are being referred for invasive investigation and intervention. ${ }^{2}$ A recent national audit in the UK of the complications of diagnostic cardiac catheterisation did not identify how many of the patients were elderly (although future data collection will do so), but some impression was gained that the severe haemodynamic upsets tended to occur more frequently in the sick elderly group. ${ }^{14}$

\section{PERCUTANEOUS TRANSLUMINAL CORONARY ANGIOPLASTY (PTCA)}

What are the results of PTCA in older patients? In all the reported series there is inevitably a selection bias which will be reflected in the success and complication rate. Initial reported successes have improved over the last decade with advances in techniques and operator experience. No doubt as new techniques such as coronary artery stenting become more widespread these will be considered, and indeed early results in elderly patients look promising. ${ }^{15}$ Initial success rates for PTCA in elderly patients are in the order of $84-96 \%$ with major complication rates of around $3-6 \%$, mortality rates of $0-2 \%$ and long-term event-free survival of $68-76 \% \cdot{ }^{16-19}$ This latter measure, however, may be unrelated to the overall success of the procedure but more to factors such as global left ventricular function, progression of the coronary disease, and development of non-cardiac disease. One of these recent studies compared results in younger and older patients and found no difference in success or complication rates, though their older group was much smaller and had significantly lower percentages of smokers and males which may have affected the results. ${ }^{18}$

\section{CORONARY ARTERY BYPASS GRAFTING (CABG)}

How does PTCA compare to CABG? Clearly the patients selected for the two procedures may differ in that patients with single-vessel disease are more likely to be referred for PTCA, and multi-vessel disease for CABG, so comparisons are difficult. In the US $50 \%$ of patients undergoing CABG are over 65 years of age and $10 \%$ are older than $75 .{ }^{20}$ In the early 1980 s, data from the Coronary Artery Surgery Study showed peri-operative mortality rates of around $5 \%$ in patients over the age of $65 .{ }^{21}$ Comparison (in a non-randomised study) of medical versus surgical treatment suggested better survival in the surgically treated group, ${ }^{22}$ particularly for those in a high-risk group. Those with mild angina, good left ventricular function and no left main stem disease fared equally well with either treatment. Data from other series show varying mortality rates depending on the number of patients included who were smokers, very elderly, had left ventricular impairment and with co-existing diseases, and whether or not the surgery was elective or emergency. Mortality figures range from $2.3 \%$ to $10.8 \%{ }^{24}$ This latter study included a number of very high risk emergency patients with mortality rates of up to $35 \%$. Most studies show some increase in the length of stay for elderly patients, usually in the order of two to three days and post-operative morbidity increases with advancing years..$^{23,25}$ Generally around $75 \%$ of patients are rendered angina-free, even at long-term follow-up.

Thus, although advanced age should not be a contra-indication for CABG, other factors likely to influence the mortality should be taken into consideration. In these days of internal markets within the health service it may be considered that cardiologists and surgeons may be reluctant to intervene in higher risk patients who may upset their procedural morbidity and mortality figures.

\section{Aortic stenosis}

The most common cause of aortic stenosis in elderly people is degenerative disease with calcification. ${ }^{26}$ It carries a high mortality if left untreated - one year survival may be as low as $57 \%{ }^{27}$

\section{PERCUTANEOUS AORTIC VALVULOPLASTY}

In the mid-1980s, with the description of successful valvuloplasty, ${ }^{28}$ hopes were raised of a useful non-surgical intervention. However, with increased experience of the technique and longer follow-up of the patients, it has emerged that the clinical and haemodynamic improvement is short-lived, with around $50 \%$ recurrence by six months, ${ }^{29}$ and the periprocedural and follow-up mortality is high at around $15 \%$ at 30 -day follow-up. ${ }^{30,31}$ It may, however, be a useful bridge for patients in whom it is felt they could be made fit for surgery, or as palliative treatment for very poor risk surgical patients. 


\section{Case history}

A 75-year-old woman had a long history of dyspnoea due to rheumatic mitral valve disease. Dyspnoea had increased so as to severely limit daily activity. Transthoracic and transoesophageal echo demonstrated severe mitral stenosis with commissural fusion and a valve area of approximately $0.5 \mathrm{~cm}^{2}$. There was mild mitral regurgitation and the mitral valve apparatus otherwise appeared suitable for balloon mitral valvuloplasty. This was performed using the Inoue balloon (see figure 3 ) and end diastolic mitral valve gradient fell from $10 \mathrm{mmHg}$ to $0 \mathrm{mmHg}$ and mean left atrial pressure from $26 \mathrm{mmHg}$ to $9 \mathrm{mmHg} ; 15$ months later she remains symptomatically improved.

\section{Box 2}

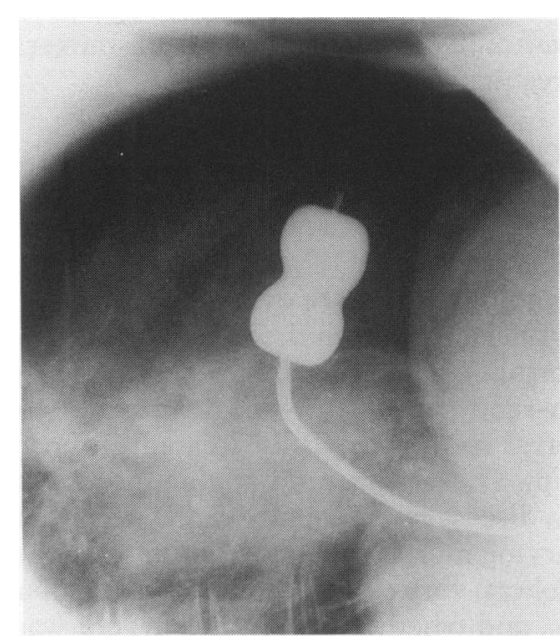

Figure 3

\section{Cardiological interventions} in the elderly

- age alone should not be a bar to appropriate cardiological investigations and treatment

- the benefits of thrombolysis for acute myocardial infarction outweight the risks in the majority of cases, yet this treatment is still being denied to some patients

- PTCA or CABG are effective, safe treatments for angina in carefully selected patients

- aortic stenosis carries a high mortality if untreated and valve replacement should be considered

- mitral valvotomy for stenosis may be successful in selected patients

- the choice of pacemaker should be determined by clinical indication and not financial constraint
AORTIC VALVE SURGERY

What are the current results of aortic valve surgery? Mortality rates for isolated aortic valve replacement vary from $3.3 \%{ }^{32}$ to $7 \% .{ }^{33}$ Patients requiring CABG in addition to valve replacement have worse outcomes varying from $7.2 \%$ to $21 \%{ }^{32-34}$. Preoperative New York Heart Association (NYHA) functional class appeared to be the only predictor of poorer outcome. Clearly, as has been stated previously, these results need to be interpreted in the light of the patient selection that will already have occurred.

\section{Mitral stenosis}

SURGICAL TREATMENT

Mitral valve replacement carries a higher mortality than aortic - around $30 \%$ in elderly patients, rising to $50 \%$ in those requiring CABG. ${ }^{33}$ In a more recent series the results were a little better, mortality for isolated valve replacement of $11 \%$ rising to $28 \%$ with CABG. ${ }^{32}$ Predictors of poor operative mortality and long term survival were NYHA class, ischaemic valvular pathology, higher pulmonary capillary wedge pressure, and poor left ventricular function.

\section{NON-SURGICAL TREATMENT}

Does percutaneous mitral valve commisurotomy have better results than the aortic procedure? It would seem so. The technique was first described in $1984,{ }^{35}$ and a small British study of 20 elderly patients with rheumatic mitral stenosis showed successful dilatation in 17 patients with no procedure-related mortality. ${ }^{36}$ At one year follow-up, clinical improvement had been maintained in 10 patients. A larger study of 99 patients showed successful outcome in 46 patients and a periprocedural mortality of $3 \% \cdot{ }^{37}$ Predictors of event-free survival included lack of calcification of the valve, NYHA class and low left atrial and pulmonary artery pressures. Thus, in suitably selected patients, it may be the treatment of choice.

\section{Symptomatic bradycardia}

Since the inception of pacemaker implantation in the 1950s it has become widely accepted for patients of all ages. At St George's Hospital London, 82\% of pacemaker implants were in patients aged over $65 .{ }^{38}$ In the UK fewer pacemakers are inserted than in other western countries - 150 per million population annually compared with around 400 per million in France and Germany. ${ }^{39}$

The indications for pacing have been summarised in guidelines produced by the American Heart Association, ${ }^{40}$ which include syncope associated with complete heart block or sinus arrest, symptomatic sick sinus syndrome and symptomatic incomplete atrioventricular (AV) block. Other possible indications would be carotid sinus syndrome and malignant vasovagal syncope where investigations demonstrated a major cardioinhibitory effect, and persistent AV block even without symptoms, as pacing appears to prolong life expectancy. ${ }^{41}$

What is currently more controversial is the choice of pacemaker. Recent British guidelines ${ }^{41}$ have suggested that the general principles to be followed are that the ventricle should be paced if there is actual or threatened AV block and the atrium should be paced or sensed unless there is a contraindication such as atrial fibrillation. Rate-responsive pacing is not essential if the patient is inactive. The working party then produced specific recommendations for types of arrhythmias. Notably, single chamber constant rate ventricular inhibited devices were not recommended as first choice for any condition, and yet in the UK in the late 1980 s around $78 \%$ of pacemakers inserted were such devices. ${ }^{42}$ Dual chamber pacing has many advantages. Restoring atrial transport improves stroke volume, heart rate can respond to effort and improve exercise capacity (providing sinus node function is normal) and it may reduce the risk of subsequent development of atrial fibrillation and systemic embolism. The pacemaker syndrome (due to asynchronous contraction of atria and ventricles) is abolished. However, given the large change in practice that would occur if the working party's recommendations were implemented, several authors have commented that there would be enormous cost implications, ranging from a $75 \%$ to a $94 \%$ increase in the pacing budget. ${ }^{38,43,44}$ Also there would be implications in terms of staff training. Monitoring the more complex devices might require that patients travel further for follow-up which might not be acceptable to elderly patients. Others feel that the benefits of optimum pacing outweigh the disadvantages. ${ }^{45}$

The debate has led some to use age of the patient as a criterion for choice of device, believing that most patients aged over 75 lead a sedentary lifestyle which would not benefit from the insertion of a more complex device. ${ }^{38}$ Whilst it may be true for a number of elderly patients, there are many over the age of 75 with very 


\begin{tabular}{|l|}
\hline Congestive heart failure: \\
Framingham study \\
\hline 1-year survival (\%) \\
men 57 \\
women 64 \\
5-year survival (\%) \\
men 25 \\
women 38 \\
Median survival (years) \\
men 1.7 \\
women 3.2 \\
\hline
\end{tabular}

Box 4 active lifestyles for whom a dual chamber, and possibly rate-responsive device would be advisable. Doctors need to be wary of using age in arbitrary fashion, particularly if the constraint to do so is largely financial.

\section{Congestive heart failure and angiotensin-converting enzyme (ACE) inhibitors}

\section{SURVIVAL}

In 1956, Bedford \& Caird demonstrated that the one year survival of elderly patients after the diagnosis of congestive heart failure was only $37 \%$ with subsequent survival similar to that of an age-matched control population. After three years, $80 \%$ of men aged 65 or more had died. ${ }^{46}$ In 1992 , a study of survival of elderly men aged over 75 years showed a similar pattern of high mortality in the first year after the onset of congestive heart failure with subsequent survival running near parallel to the control population. ${ }^{47}$ Mortality in this study was $28 \%$ in the first year. Survival data from the Framingham study are shown in box 4 . Overall mortality has not changed significantly during the 40 years of study. Mean age at diagnosis was 57 years in the 1950s, 66 years in the 1960s, 72 years in the 1970s, and 76 years in the 1980s. The reason for the increasing age at diagnosis is the subject of a separate investigation..$^{48}$ Yusuf has speculated that antihypertensive treatment may postpone the development of congestive heart failure by several decades. ${ }^{49}$

\section{INFLUENCE OF ACE INHIBITORS ON SURVIVAL}

In 1986, the Cooperative Vasodilator-Heart Failure Trial (V-HeFT I) demonstrated that the addition of the combination of the vasodilators hydralazine and isosorbide dinitrate reduced mortality in patients with mild to moderate heart failure. Compared to placebo, the reduction in mortality after one year was $38 \%$, $25 \%$ after two years and $28 \%$ over the mean follow-up period of 2.3 years. The group treated with prazosin showed no difference in mortality compared with placebo which showed a one year mortality of $19.5 \%$ and a four year mortality of $54 \%{ }^{50}$ This was followed up by a second trial (V-HeFT-II) which compared the effect of enalapril, an ACE inhibitor, with hydralazine-isosorbide dinitrate in similar patients (box 5). ${ }^{51}$ Most of the benefit occurred in the first year with survival curves running parallel thereafter. Unlike most other studies, reduction in mortality was attributable to a reduction in sudden death rather than pump failure. Ejection fraction was increased in the hydralazine-isosorbide group more than the enalapril group and peak exercise oxygen consumption and performance was increased only in the hydralazine-isosorbide group. The authors suggested that the profile of effects might be enhanced if the regimens were used in combination.

In 1987, the CONSENSUS Trial Study Group reported the effect of the addition of enalapril compared to placebo in patients with severe congestive heart failure (NYHA class IV)..$^{52}$ After six months, mortality in the placebo group was $48 \%$ whereas in the enalapril group mortality was $29 \%$ : a $40 \%$ reduction. The trial was stopped as a consequence. The improved survival was predominantly due to a reduction in the progression of congestive heart failure with the effect most marked among those patients with marked neurohormonal activation. ${ }^{53}$ Similar findings were found in the V-HeFT II study, even though the reduction in mortality in this study was attributed predominantly to a reduction in sudden death rather than to pump failure. ${ }^{54}$ Two-year follow-up of the patients from the CONSENSUS study (after breaking the code) demonstrated that the patients who started in the enalapril group continued to have a significantly lower mortality than those who started on placebo, even though enalapril was made available to all at this stage. The carry-over effect of enalapril lasted 12 to 15 months after the end of the blinded trial. Of the survivors of the blinded study, enalapril resulted in improved subsequent survival even though the patients in this group were sicker at baseline. ${ }^{55}$

The Studies of Left Ventricular Dysfunction (SOLVD) investigators studied the effect of enalapril on mortality and admission rates to hospital on symptomatic patients (mostly NYHA class II \& II) with low ejection fractions of $35 \%$ or less over a period of four years. ${ }^{56}$ The addition of enalapril reduced overall mortality by $16 \%$ compared with placebo. It was estimated that treating 1000 patients with an ACE inhibitor in conjunction with conventional therapy for three years could prevent 50 premature deaths and 350 admissions to hospital. As with the CONSENSUS trial, reduction in mortality was mainly due to a reduction $(22 \%)$ in the risk of dying from progressive heart failure, even though more patients on placebo were taking other vasodilators. In asymptomatic patients with ejection fractions of $35 \%$ or less, enalapril reduced the risk of heart 
failure and the rate of related admissions to hospital by $20 \%$ compared to placebo. ${ }^{57}$ There was also a trend towards fewer deaths.

Experimental and clinical studies have demonstrated progressive left ventricle enlargement and dysfunction after myocardial infarction. ${ }^{58,59}$ The degree of left ventricle dysfunction correlates highly with subsequent mortality. ${ }^{60}$ The Survival and Ventricular Enlargement (SAVE) trial studied whether captopril given 3-16 days after acute myocardial infraction would lessen deterioration in cardiac performance and improve clinical outcome in patients with left ventricular dysfunction but without overt heart failure over a period of two to five years. ${ }^{61}$ Compared with placebo, overall reduction in mortality was $19 \%$, cardiovascular deaths were reduced by $21 \%$ and mortality due to progressive heart failure by $36 \%$. Although progressive left ventricular dysfunction was reduced in the captopril group by $15 \%$, a proportional-hazards model for mortality from all causes demonstrated a significant influence on mortality independent of age, ejection fraction, history of myocardial infarct, sex, baseline arterial blood pressure and use of thrombolytic therapy, aspirin or $\beta$-blockers. The Acute Infarction Ramipril Efficacy (AIRE) study investigators have recently shown a similar benefit of an ACE inhibitor given post-infarct to patients with clinical evidence of heart failure. ${ }^{62}$ Over an average follow-up of 15 months, compared with placebo, ramipril given 3-9 days post-infarct resulted in an overall reduction in mortality of $27 \%(17 \% v 23 \%)$. Unusually, this study demonstrated a reduction in all-cause mortality in female patients of $31 \%$. The survival curves diverged early and continued to diverge throughout the study. Patients in whom an ACE inhibitor was considered necessary were excluded. In contrast, the CONSENSUS II Study ${ }^{63}$ was stopped before the intended numbers of patients were recruited as more patients died on enalaprilat/enalapril than placebo. In that study, all patient were randomised to receive drug or placebo within 24 hours of acute myocardial infarction. This it would seem that ACE inhibition is beneficial, but only to selected patients three or more days after myocardial infarction.

Can the results of these studies be extrapolated to elderly people with congestive heart failure? The average age in the CONSENSUS study was 70 years and in the AIRE study 65 years; in the other studies, the average ages ranged from 58 to 61 . The ageing human heart is typified by diminished ventricular compliance and prolongation of myocardial relaxation time. ${ }^{64}$ The subsequent higher left ventricular diastolic pressures at rest and exercise may cause congestive heart failure even in the presence of normal systolic function. Normal left ventricular ejection fractions are found in $41 \%$ to $47 \%$ of elderly patients with congestive cardiac failure. ${ }^{65,66}$ In those over 80 years of age, over $50 \%$ have normal or near normal systolic function. ${ }^{67}$ Congestive heart failure due to diastolic dysfunction typically has a rapid onset. ${ }^{64,68}$ In older people the relationship between left ventricular systolic function and survival is not clear. Some authors find no correlation ${ }^{47,68}$ whilst others do. ${ }^{66,69}$ The differences in results may be explained by the presence or absence of coronary artery disease. Older patients with coronary artery disease in the V-HeFT studies fared badly whereas older age alone did not shorten survival. ${ }^{70}$ A 5.8-year follow-up of patients with isolated left ventricular diastolic dysfunction and normal coronary arteries suggested a low cardiac mortality, but substantial morbidity. Over half developed symptoms of congestive heart failure during follow-up. ${ }^{71}$ Agents that may enhance diastolic ventricular filling in the presence of normal systolic function include calcium channel antagonists, $\beta$-adrenergic antagonists and ACE inhibitors. Vigorous preload reduction and the use of digitalis should be avoided. ${ }^{64}$ The use of calcium antagonists has been studied ${ }^{72}$ but the negative inotropic effect of these agents and of $\beta$-adrenergic antagonists limits their use. In V-HeFT I and II, increased age $(>65)$ was associated with higher blood pressure, slower heart rate, higher left ventricular ejection fraction, poorer peak exercise performance, and more peripheral oedema. In both studies, the favourable effect of vasodilatation was less apparent in the older age group. However, ageing alone did not adversely effect mortality in male patients $<75$ years old (older patients were excluded) ${ }^{70}$ The authors concluded that this provided a mandate for intensive medical therapy for all patients with heart failure, regardless of age.

In a small study of elderly patients (average age 80 ) with congestive heart failure with normal ejection fractions, abnormal diastolic relaxation and priormyocardial infarction, treatment with enalapril improved NYHA class, reduced cardiothoracic ratio, increased treadmill exercise duration, improved left ventricular systolic and diastolic function and reduced left ventricular mass. ${ }^{66}$

ACE INHIBITORS COMPARED WITH OTHER AGENTS

ACE inhibitors are an advance, albeit modest compared with cardiac transplantation. ${ }^{73}$ This contrasts with the disappointing results from trials with other 
agents. Prazosin was associated with a worse prognosis, particularly in older subjects $^{70}$ and hydralazine alone showed no benefit above placebo. ${ }^{74}$ The role of nitrates in heart failure has yet to be established. ${ }^{75}$ In V-HeFT II, ACE inhibition was superior to the combination of hydralazine and isosorbide dinitrate. ${ }^{51}$

Why are ACE inhibitors superior to other vasodilators? High concentrations of angiotensin and noradrenaline are toxic to myocardial cells. ACE inhibition may reduce injury and thus reduce cell necrosis, fibrosis, and disease progression. ${ }^{76}$ The main mechanism of neurohormonally mediated damage may involve oxygen free radicals. ${ }^{77}$ This might explain why ACE inhibitors reduce mortality to a greater extent than direct-acting vasodilators, even though the latter produce superior haemodynamic effects ${ }^{51}$ and why the reduction in mortality with ACE inhibitors is greater in those patients with the most marked neurohormonal activation. ${ }^{53}$

Cyclic-AMP-dependent inotropic agents ( $\beta$-adrenergic agonists and phosphodiesterase inhibitors) are associated with increased mortality, which appears to be dose-related. ${ }^{78}$ Any beneficial effect of positive inotropes may be related to their other properties at low doses, such as peripheral vasodilatation (milrinone, pimobendan), anti-arrhythmic effects (vesnarinone), or neurohormonal effects (digoxin) ${ }^{76,79}$ Flosequinan was found to have cyclic-AMP-dependent positive inotropic effects due to phosphodiesterase inhibition ${ }^{80}$ in addition to being a putative direct-acting balanced arterial and venous vasodilator. ${ }^{81}$ In animal studies, Greenberg found the drug to be 4.6 times more potent as a positive inotrope than as a vasodilator ${ }^{82}$ and he postulated that flosequinan may adversely affect myocardial work and wall tension. ${ }^{83}$ Excess mortality was seen in patients receiving $100 \mathrm{mg}^{84}$ and an increase in hospital admissions in those receiving $75 \mathrm{mg}$, whereupon the drug was voluntarily withdrawn from sale. ${ }^{85}$

Digoxin exerts its effect by binding to sarcolemmal $\mathrm{Na} / \mathrm{K}$-dependent ATPase and is cyclic-AMP independent. Unlike cyclic-AMP-dependent agents, digoxin reduces the activation of the sympathetic nervous system and the reninangiotensin system independently of its haemodynamic actions. ${ }^{77}$ The effect of digoxin on survival is not known, but these properties would be expected to have an advantageous effect. A large study in the US and Canada is addressing this issue and should be complete by mid- $1995 .^{86} \mathrm{However}$, the withdrawal of digoxin therapy from patients in chronic heart failure and in sinus rhythm with decreased ejection fractions receiving a diuretic and ACE inhibitor has recently been shown to result in a relative risk of worsening heart failure of $5.9 .{ }^{87} \mathrm{~W}$ ithdrawal of digoxin from elderly patients with normal ejection fractions is not associated with any deterioration. ${ }^{88}$

Although the evidence is limited, it seems that the use of an ACE inhibitor in addition to diuretics is appropriate in elderly patients with congestive heart failure with both systolic and diastolic dysfunction. Because elderly patients are more susceptible to the side effects and complications of ACE inhibitors, these agents must be introduced with caution, particularly in patients already taking high doses of diuretic and other hypotensives (including antidepressants), ${ }^{89,90}$ Patients who cannot tolerate an increased dose of ACE inhibitor may benefit from the addition of spironolactone, especially when plasma or urinary aldosterone levels are high. ${ }^{91,92}$ The role of digoxin in controlling the ventricular rate in atrial fibrillation is not disputed. There is increasing evidence that its use is indicated when there is reduced left ventricular ejection fraction, but not when congestive heart failure is due to diastolic dysfunction. With a life expectancy shorter than in many common malignancies, ${ }^{48}$ investigation should include an echocardiogram in order to give optimum treatment in all cases. ${ }^{93}$ More study of the use of ACE inhibitors and other agents in the elderly is needed.

1 Fourth Report of a Joint Cardiology Committee. Provision of services for the diagnosis and treatment of heart disease. Br Heart $\mathcal{F} 1992 ; 67$ 106-16.

2 Report of a working group of the Royal College of Physicians. Cardiological intervention in 25: $197-205$.

3 Wong JB, Salem DN, Parker SG. You're never too old. $N$ Engl $F$ Med 1993; 328: 971-4.

4 ISIS-2. Collaborative group randomised trial of intravenous streptokinase, oral aspirin, both or intravenous streptokinase, oral aspirin, both or
neither among 17187 cases of suspected acute neither among 17187 cases of suspected acute
myocardial infarction. Second International Study of Infarct Survival (ISIS-2). Lancet, 1988; 2: 349-60.

5 AIMS Trial Study Group. Long-term effects of intravenous anistreplase in acute myocardial infarction: final report of the AIMS study. Lancet 1990, 335: 427-31.
6 Wilcox RG Olsson CG, Skene AM, et al. Trial of tissue phasminogen activator for mortality reduction in acute myocardial infarction. AngloScandinavian study of early thrombolysis (ASSET). Lancet, 1988; 2: 525-30.

7 Weaver WD, Litwin PE, Martin JS, et al. Effect of age on use of thrombolytic therapy and mortality in acute myocardial infarction: the
MITI project group. $\exists \mathrm{Am}$ Coll Cardiol 1991; 18: 657-62.

8 Dudley NJ, Burns $E$. The influence of age on policies for admission and thrombolysis in coronary care units in the United Kingdom. Age onary care units in the
Ageing 1992; 21: $95-8$.

9 Haigh R, Castelden M, Woods K, et al. Management of myocardial infarction in the elderly: ment of myocardial infarction in the elderly:

10 Topol EJ, Califf RM. Thrombolytic therapy for elderly patients. N Engl f Med 1992; 327: 45-7.
11 De Jaegere, Arnold AA, Balk AH, Simoons ML. Intracranial haemorrhage in association with thrombolytic therapy: incidence and clinical predictive factors. $\mathcal{f} \mathrm{Am}$ Coll Cardiol 1992; 19:
289-94.

12 ISIS-3 (Third International Study of Infarct Survival) Collaborative Group. A randomized comparison of streptokinase vs tissue plasminogen activator $v s$ anistreplase and of aspirin plus heparin $v s$ aspirin alone among 41299 cases of suspected acute myocardial infarction. Lancet of suspected acute my2; 339: 753-70.

13 Backes RJ, Gersh BJ. The treatment of coronary artery disease in the elderly. Cardiovasc Drugs Ther 1991; 5: 449-56. 
14 De Bono D, on behalf of the Joint Audit Committee of the British Cardiac Society and the Royal College of Physicians of London. Complications of diagnostic cardiac catherisation: results from 34041 patients in the U.K. confidential enquiry into cardiac catheter complications. Br Heart $\mathcal{f}$ 1993; 70: 297-300.

15 Maiello L, Gianrossi R, Colombo A. Initial results or coronary stenting in patients aged 70
and over. Cardiol Elderly 1993; 1: 149-51.

16 De Jaegere P, de Feyter P, van Domburg R, De Jaegere $P$, de Feyter $P$, van Domburg R,
Suryapranata H, van den Brand $M$, Serruys Suryapranata $H$, van den Brand $M$, Serruys
$P W$. Immediate and long-term results of percutaneous coronary angioplasty in patients aged 70 and over. Br Heart $\mathcal{F}$ 1992; 67: 138-43.

17 Bonnier H, de Fries C, Michels R, El Garnal M. Initial and long-term results of coronary angioplasty and coronary bypass surgery in patients
75 or older. Br Heart $\mathcal{f} 1993 ; 70: 122-5$.

18 Ilia R, Kolanski D, Setero J, et al. Percutaneous transluminal coronary angioplasty in the elderly: initial results and

19 Bedotto JB, Rutherford BD, McConahay DR, et al. Results of multivessel transluminal coronary angioplasty in persons aged 65 years and older. Am $\mathcal{f}$ Cardiol 1991; 67: 1051-5.

20 Cosgrove DM. Surgical myocardial revascularisation. Cardiol Elderly 1993; 1: 71-6.

21 Gersh BJ, Kronmal RA, Frye RL. Coronary arteriography and coronary artery bypass arteriography and coronary artery bypass surgery: morbidity and mortality in patients aged 65 years and older. A report from the 1983; 67: 483-90.

22 Gersh BJ, Kronmal RA, Schaff HV, Frye RL, Ryan RJ, Mock MB. Comparison of coronary artery bypass surgery and medical therapy in patients 65 years of age or older: a nonrandomised study from the Coronary Artery Surgery Study (CA

23 Loop FD, Lytle BW, Cosgrove DM, et al. Coronary artery bypass graft surgery in the elderly: indications and outcome. Cleveland Clin f Med 1988; 55: 23-4.

24 Horvath KA, Disesa VJ, Peigh PS, Couper GS, Collins JJ, Cohn LH. Favourable results of coronary artery bypass grafting in patients older coronary artery bypass grafting in patients older 99: $92-6$.

25 Edwards FH, Taylor AJ, Thompson L. Current status of coronary artery operation in sep-

26 Roelandt JRTC, Meeter K. Diagnosis and management of valvular heart disease in the elderly. Cardiol Elderly 1993; 1: 235-43.

27 Beatt KJ. Balloon dilatation of the aortic valve in adults: a physicians view. Br Heart $\mathcal{F} 1990$; 63: 207-8.

28 Cribier A, Savin T, Saoudi N, Rocha P, Berland J, Letac B. Percutaneous transluminal valvuloplasty of acquired aortic stenosis in elderly patients: an alternative to valve replacement? patients: an alternative

29 Legrand V, Beckers J, Fastrez M, Marcelle P, Marchal C, Kulbertus HE. Long-term followup of elderly patients with severe aortic stenosis treated by balloon aortic valvuloplasty. Importreated by balloon aortic valvuloplasty. Imporafter dilatation. Eur Heart $\mathcal{F} 1991 ; 12: 451-7$.

30 Bernard Y, Etievent J, Mourand JL, et al. Long-term results of percutaneous aortic valvuloplasty compared with aortic valve replacement inpatients more than 75 years old. $\mathcal{F} \mathrm{Am}$ Coll Cardiol 1992; 20: 796-801.

31 McKay CR, Waller BF. Current status of balloon valvuloplasty. Cardiol Elderly 1993; 1: 77-85.

32 Davis EA, Gardner JJ, Gillinov AM, et al. Valvular disease in the elderly: influence on surgical results. Ann Thorac Surg 1993; 55: 333-8.

33 Tsai TP, Matloff JM, Chaux A, et al. Combined valve and coronary artery bypass procedures in septuagenarians and octogenarians: results in 120 patients. Ann Thorac Surg 1986; 42: 681-4.

34 Levinson JR, Akins CW, Buckley MJ et al. Octogenarians with aortic stenosis: outcome after aortic valve replacem

5 Inoue $K$, Owaki T, Nakamura T, Kitamura F, Miyamoto N. Clinical application of transvenous mitral commisurotomy by a new balloon catheter. F Thorac Cardiovasc Surg 1984; 87: 394-402.

36 Shaw TRD, Elder AT, Flapan AD, Essop AR. Mitral balloon valvuloplasty for patients aged over 70 years: an alternative to surgical treatment. Age Ageing 1991; 20: 299-303.

37 Tuczu EM, Block PC, Griffin BP, Newell JB, Palacios IF. Immediate and long-term outcome of percutaneous mitral valvotomy in patients of percutaneous mitral valvotomy in patients aged 65
38 de Belder MA, Linker NJ, Jones S, Camm AJ, Ward DE. Cost implications of the British Pacing and Electrophysiology Group's mendations for pacing. BMF 1992; 305: 861-5.

39 World Survey Data. PACE 1987; 10: 769-77.

40 Frye RL, Collins JJ, De Sanchs RW. Guidelines for permanent pacemaker implantation May 1984. A report of the joint American College of Cardiology/American Heart Association Task Force on assessment of cardiovascular proceForce on assessment of cardiovascular proce
dures. $₹$ Am Coll Cardiol 1984; 4: 434-42.

41 Report of a working party on the British Pacing and Electrophysiology Group. Recommendations for pacemaker prescription for symptomatic bradycardia Br Heart $f$ 1991; 66:

42 Bernstein $\mathrm{AD}$, Camm AJ, Fletcher RD, et al. The NASPE/BPEG generic pacemaker code for antibradyarrhythmia and adaptive rate pacing 10: 794-9.

43 Ray SG, Griffith MJ, Jamieson S, Bexton RS, Gold RG. Impact of the recommendations of the British Pacing and Electrophysiology Group on pacemaker prescription and on the immediate costs of pacing in the Northern Region. Br Heart f 1992; 68: 531-4.

44 Petch MC. Who needs dual chamber pacing: $B M F$ 1993; 307: 215-6.

45 Nathan AW, Davies DW. Is VVI pacing outmoded? Br Heart $\mathcal{f}$ 1992; 67: 285-8.

46 Bedford PD, Caird FI. Congestive heart failure in the elderly. Qf Med 1956; 99: 407-26.

7 Taffet GE, Teasdale TA, Bleyer AJ, Kutka NJ, Luchi RJ. Survival of elderly men with congestive heart failure. Age Ageing 1992; 21: 49-55.
Ho KKL, Anderson KM, Kannel WB, Grossman W, Levy D. Survival after the onset of Study subjects. Circulation 1993; 88: 107-15.

49 Yusuf S, Thom T, Abbott RD. Changes in hypertension treatment and in congestive heart failure mortality in the United States. Hypertension 1989; 13 ( 5 suppl): 174-9.

50 Cohn JN, Archibald DG, Ziesche S, et al. Effect of vasodilator therapy on mortality in chronic congestive heart failure: results of a Veterans Administration Cooperative Study. N Engl $\mathcal{f}$ Med 1986; 314: 1547-52.

51 Cohn JN, Johnson G, Ziesche S, et al. A comparison of enalapril with hydralazineisosorbide dinitrate in the treatment of chronic congestive heart

52 The CONSENSUS Trial Study Group. Effects of enalapril on mortality in severe congestive heart failure. Results of the Cooperative North Scandinavian Enalapril Survival Study (CON-

Swedber . Engl f Med 1987; 316: 1429-35. sen $L$, for the CONSENSUS Trial Study Group. Hormones regulating cardiovascular function in patients with severe congestive heart failure and the relation to mortality. Circulation 1990; 82: 1730-6.

54 Francis GS, Cohn JN, Johnson G, Rector TS, Goldman S, Simon A, for the V-HeFT II VA Cooperative Studies Group. Plasma norepinephrine, plasma renin activity and congestive heart failu
VI): VI40-8

55 Kjekshus J, Swedberg K, Snapinn S, for the CONSENSUS Trial Group. Effects of enalapril on long-term mortality in severe cong heart failure. Am $\mathcal{f}$ Cardiol 1992; 69: 103-7.

56 The SOLVD Investigators. Effect of enalapril on survival in patients with reduced left ventricular ejection fractions and congestive heart failure. N Engl f Med 1991; 325: 293-302.

57 The SOLVD Investigators. Effect of enalapril on mortality and the development of heart failure in asymptomatic patients with reduced left ventricular ejection fractions. $N$ Engl $₹ \mathrm{Med}$ 1992; 327: 685-91.

58 Pfeffer MA, Braunwald E. Ventricular remodeling after myocardial infarction: experimental bservations and clinical implications. Circulaion 1990; 81: 1161-72.

59 Jeremy RW, Allman KC, Bautovitch G, Harris PJ. Patterns of left ventricular dilation during the six months after myocardial infarction. $\mathcal{F} \mathrm{Am}$ Coll Cardiol 1989; 13: 304-10.

60 White HD, Norris RM, Brown MA, Brandt PWT, Whitlock RML, Wild CJ. Left ventricular end-systolic volume as the major determinant of survival after recovery from myocardial infarction. Circulation 1987; 76: 44-51.

61 Pfeffer MA, Braunwald E, Moye LA, et al, on behalf of the SAVE Investigators. Effect of captopril on mortality and morbidity in patients with left ventricular dysfunction after myocardial infarction. Results of the Survival and 1992; 327: 669-77.

62 The Acute Infarction Ramipril Efficacy (AIRE) Study Investigators. Effect of ramipril on mortality and morbidity of survivors of acute myocardial infarction with clinical evidence of heart failure. Lancet 1993; 342: 821-8.

63 Swedberg K, Held P, Kjekjus J, et al, on behalf of the CONSENSUS II Study Group. Effects of early administration on enalapril on mortality in patients with acute myocardial infarction. Results of the Cooperative North Scandinavion. Enalapril Survival Study II (CONSENSUS Enalapril Survival Study II (CONSE

64 Wei JY. Age and the cardiovascular system. $N$ Engl $f$ Med 1992; 327: 1735-9.

65 Wong WF, Gold S, Fukuyama O, Blanchette PL. Diastolic dysfunction in elderly patients with congestive cardiac failure. Am f Cardiol 1989; 63: 1526-8.

66 Aronow WS, Kronzon I. Effect of enalapril on congestive heart failure treated with diuretics in elderly patients with prior myocardial infarction and normal left ventricular ejection fraction. $A m$ f Cardiol 1993; 71: 602-4.

67 Luchi RJ, Snow E, Luchi JM, Nelson CL, Pircher FJ. Left ventricular function in hospitalised geriatric

68 Setaro JF, Soufer R, Remetz MS, Perlmutter RA, Zaret BL. Long-term outcome in patients with congestive heart failure and intact systolic left ventricular performance. Am F Cardiol 1992; 69: $121-6$.

69 Cohn JN, Johnson G. Heart failure with normal ejection fraction: the V-HeFT study. Circulation 1990; 81 (suppl III): III48-53.

70 Hughes CV, Wong M, Johnson G, Cohn JN, for the V-HeFT VA Cooperative Studies Group. Influence of age on mechanisms and prognosis of heart failure. Circulation 1993; 87 (suppl VI): VI111-7.

71 Brogan WC, Hillis LD, Flores ED, Lange RA. The natural history of isolated left ventricular function. $A m$ F Med 1992; 92: 627-30.

72 Setaro JF, Zaret BL, Schulman DS, Black HR Soufer R. Usefulness of verapamil for congestive heart failure associated with abnormal left ventricular diastolic filling and normal left ventricular systolic performance. Am $\mathcal{F}$ Cardiol 1990; 66: $981-6$.

73 Townend JN, Littler WA. Angiotensin converting enzyme inhibitors in heart failure: how good are they? Br Heart $\mathcal{f} 1993$; 69: 373-5.

74 Franciosa JA, Weber KT, Levine TB. Hydralazine in the long term treatment of chronic
heart failure: lack of difference from placebo. Am Heart f 1982; 104: 587-94.

75 Cohn JN. Mechanisms of action and efficacy of nitrates in heart failure. Am f Cardiol 1992; 70: 88B-92B.

76 Packer M. Treatment of chronic heart failure. Lancet 1992; 340: 92-5.

77 Packer M. Pathophysiology of chronic heart failure. Lancet 1992; 340: 88-92.

78 Feldman AM, Bristow MR, Parmley WW, et al. Effects of vesnarinone on morbidity and mortality in patients with heart failure. Vesnarinone Study Group. N Engl f Med 1993; 329: 149-55.

79 Packer M. The development of positive inotropic agents for chronic heart failure: how have we gone astray? f $\mathrm{Am}$
suppl $\mathrm{A}): 119 \mathrm{~A}-126 \mathrm{~A}$.

80 Gristwood RW, Beleta J, Bou J, et al. Studies on the cardiac actions of flosequinan in vitro. $\mathrm{Br} \mathcal{F}$ Pharmacol 1992; 105: 985-91.

81 Cowley AJ, Wynne RD, Hampton JR. The effects of BTS 49465 on blood pressure and peripheral and venous tone in normal volunteers. $\mathcal{F}$ Hypertension 1984; 2 (suppl 3): 547-9.

82 Greenberg S, Touhey B. Positive inotrophy contributes to the haemodynamic mechanism of flosequinan (BTS 49465) in the intact dog. $f$ Cardiovasc Pharmacology 1990; 15: 900-10

83 Greenberg S, Touhey B, Paul J. Effect of losequinan (BTS 49465) on myocardial oxygen consumption. Am Heart $\mathcal{F}$ 1990; 119: 1355-66.

84 Busson M. Manoplax (flosequinan) - increased mortality at a dose of $100 \mathrm{mg}$. Boots Pharmaceuticals, 26 April 1993 (letter)

85 Busson M. Withdrawal of Manplax (flosequinan). Boots Pharmaceuticals 17 July 1993 (letter).

86 Smith TW. Digoxin in heart failure. $N$ Engl f Med 1993; 329: 51-3.

87 Packer M, Gheordhiade M, Young JB, et al. Withdrawal of digoxin from patients with 
89 Diggory $\mathrm{P}$, Homer A, Liddle J, et al. Medicine in the elderly. Postgrad Med f 1991; 67: 423-45.

90 Luchi RJ, Taffet GE, Teasdale TA. Congestive heart failure in the elderly. $\mathcal{F} \mathrm{Am}$ Geriatr Soc 1991; 39: 810-25.

91 Dahlstrom U, Karlsson E, Captopril and

spironom spironolactone therapy for refractory congestive
heart failure. Am $₹$ Cardiol 1993; 71: 29A-33A.
92 Van Vliet AA, Donker AJ, Nauta JJ, Verheugt FW. Spironolactone in congestive heart failure refractive to high-dose loop diuretic and lowdose angiotensin converting enzyme inhibitor. Am $\mathcal{f}$ Cardiol 1993; 71: 21A-28A.
93 Yiannakou JY, Gray KE, Winter RJ. ACE inhibitors and heart failure (letter). Lancet 1992; 339: 687 . 